\title{
Competição de Cultivares de Capim-Elefante (Pennisetum purpureum, Schum.) e de Híbridos de Capim-Elefante x Milheto (Pennisetum americanum (L.) Leeke) sob Pastejo
}

\section{Mário de Andrade Lira ${ }^{1}$, José Carlos Batista Dubeux Júnior ${ }^{2}$, Cleomines Fonseca de Oliveira ${ }^{3}$, José Nildo Tabosa ${ }^{4}$}

\begin{abstract}
RESUMO - Neste estudo, sete cultivares de capim-elefante e sete híbridos de capim-elefante com milheto foram avaliados sob condições de pastejo. As características avaliadas foram produção de matéria seca (PMS), altura da planta (AP), diâmetro do colmo (DC), relação lâmina foliar/colmo (LF/C), produção de lâmina foliar (PLF), número de perfilhos basilares (NPB) e axilares (NPA), além da relação perfilhos axilares/perfilho basilar (PA/PB). Os resultados evidenciaram maiores PMS, PLF, AP, DC e LF/C para o grupo das cultivares, quando comparado com o grupo dos híbridos. Os valores foram 6,95 t de MS/ha.ano, 5,36 t de MS/ha.ano, 1,43 m, 9,62 mm e 4,86 para o grupo das cultivares e 3,80 t de MS/ha.ano, 2,49 t de MS/ha.ano, 0,99 m, 4,72 mm e 3,08 para o grupo dos híbridos, respectivamente. Os híbridos, entretanto, apresentaram maior NPB e NPA, mas a relação PA/PB foi semelhante em ambos os grupos. De maneira geral, as cultivares de capim-elefante mostraram alto potencial para exploração sob pastejo, se comparadas com o grupo dos híbridos.
\end{abstract}

Palavras-chave: avaliação de pastagens, capim-elefante, forragicultura, híbrido capim-elefante x milheto, milheto

\section{Evaluation of Elephant Grass Cultivars (Pennisetum purpureum, Schum.) and Pearl Millet (Pennisetum americanum (L.) Leeke) x Elephant Grass Hybrids under Grazing Conditions}

\begin{abstract}
In this study, seven elephant grass cultivars and seven Pearl Millet x elephant grass hybrids were evaluated under grazing conditions. The evaluated characteristics were dry matter yield (DMY), forage height (FH), stem diameter (SD), leaf blade/stem ratio (LB/S), leaves blade dry matter yield (LBDMY), basal tillers number (BTN), lateral tillers number (LTN) and lateral tillers/basal tiller ratio (LT/BT). The results showed higher DMY, LBDMY, FH, SD, and LB/S for the cultivars group, as compared to the hybrids group. The values were $6.95 \mathrm{t}$ of DM/ha.year, $5.36 \mathrm{t}$ of DM/ha.year, $1.43 \mathrm{~m}, 9.62 \mathrm{~mm}$ and 4.86 for the cultivars group and $3.80 \mathrm{t}$ of DM/ha.year, $2.49 \mathrm{t}$ of DM/ha.year, $.99 \mathrm{~m}, 4.72 \mathrm{~mm}$ and 3.08 for the hybrids group, respectively. However, the hybrids showed higher BTN and LTN. The LT/BT ratio was similar in both groups. In general, the elephant grass cultivars showed a higher potential for grazing utilization, if compared to the hybrids group.
\end{abstract}

Key Words: pasture evaluation, elephant grass, forage crops, elephant grass x pearl millet hybrid, pearl millet

\section{Introdução}

O capim-elefante (Pennisetum purpureum, Schum.), forrageira de elevado potencial produtivo (CORSI, 1993), é bastante cultivado no Estado de Pernambuco (ANDRADE, 1993). No entanto, é predominantemente utilizado sob a forma de capineiras, apesar de resultados de pesquisa evidenciarem seu potencial de uso sob pastejo nas condições da Zonada-Mata de Pernambuco (LIRA et al., 1990). Atualmente, cresce o interesse dos pecuaristas pela utilização dessa forrageira sob pastejo, principalmente nessa região e em áreas irrigadas. Essa demanda ocorre em virtude da intensificação do sistema produtivo em algumas propriedades, sendo o capim-elefante sob pastejo uma das alternativas, visto que a exploração sob corte implica em maiores custos com mão-deobra, além de qualidade inferior da forragem nas freqüências de corte normalmente utilizadas (DERESZ et al., 1998). Por outro lado, a exploração sob pastejo permite que o animal selecione uma dieta mais rica, além da redução nos custos operacionais (MARTINS e FONSECA, 1998). Vale salientar que, com o pastejo, também ocorre ciclagem dos nutrientes no ecossistema da pastagem (MONTEIRO e WERNER, 1994). Apesar disso, os trabalhos de melhoramento do capim-elefante e de seus híbridos com milheto têm sido conduzidos exclusivamente sob corte. Assim, o efeito do animal sobre os vários genótipos, que corresponde à fase 2 do esquema de melhoramento proposto por VALLE e SOUZA (1995), nunca foi realizado em Pernambuco. Além disso, todo

${ }^{1}$ Engoํ. Agrônomo, Ph.D., Pesquisador do IPA, bolsista do CNPq.

${ }^{2}$ Engo. Agrônomo, MS, Professor Assistente do Depto. Zootecnia/UFRPE, E-mail: dubeux@netpe.com.br

${ }^{3}$ Engo ${ }^{\circ}$. Agrônomo, aluno do Mestrado em Produção Animal da UFRPE.

${ }^{4}$ Engo. Agrônomo, MS, Pesquisador do IPA, bolsista do CNPq. 
processo de melhoramento deve ser dinâmico, incluindo a diversificação da base genética, a realização de novos cruzamentos e a avaliação dos germoplasmas introduzidos e gerados.

$\mathrm{O}$ termo milheto refere-se a qualquer um dos cereais de grão pequeno, utilizado para alimentação animal ou humana. Estão incluídos nessa denominação cerca de 14 espécies e 10 gêneros da família Gramineae (MACIEL e TABOSA, 1982). O milheto utilizado no programa de melhoramento genético do IPA, que originou os híbridos avaliados neste trabalho, foi o Pennisetum americanum (L.) Leeke. Um dos objetivos iniciais do programa de geração de híbridos de capim-elefante com milheto foi associar a perenidade e produtividade do capim-elefante com a qualidade e resistência à seca do milheto. Este material, no entanto, nunca havia sido avaliado sob pastejo nas condições edafoclimáticas de Pernambuco. GOMIDE et al. (1976) avaliaram quatro variedades de capim-elefante e oito híbridos de capim-elefante com milheto no Triângulo Mineiro. A avaliação, no entanto, foi sob corte, tendo os resultados demonstrado superioridade das variedades sobre os híbridos.

Este trabalho objetivou avaliar cultivares de capim-elefante e híbridos de capim-elefante com milheto, sob pastejo, nas condições edafoclimáticas da Zonada-Mata de Pernambuco.

\section{Material e Métodos}

O experimento foi realizado na Estação Experimental do Cedro, pertencente à Empresa Pernambucana de Pesquisa Agropecuária - IPA, localizada em Vitória de Santo Antão, Zona da Mata de Pernambuco. As coordenadas geográficas da Estação são Latitude $08^{\circ} 08^{\prime} 00^{\prime \prime}$ e Longitude $35^{\circ} 22^{\prime} 00^{\prime \prime}$ WGr. A altitude média do município é de $146 \mathrm{~m}$. A precipitação pluvial em 1996 foi de 1016 mm e em 1997, 1049 mm, com concentração entre março e agosto. $\mathrm{O}$ solo do local do experimento é um Podzólico Vermelho Amarelo, cuja análise química realizada em uma amostra coletada antes do início do experimento, seguindo metodologia descrita pela EMBRAPA (1979), revelou os seguintes resultados: $\mathrm{pH}, 6,8 ; \mathrm{Ca}^{++}, 1,60 \mathrm{Meq} / 100$ $\mathrm{g}$ de solo; $\mathrm{Mg}^{++}, 1,35 \mathrm{Meq} / 100 \mathrm{~g}$ de solo; $\mathrm{K}^{+}, 0,05 \mathrm{Meq} /$ $100 \mathrm{~g}$ de solo; $\mathrm{Al}^{+++}, 0,00 \mathrm{Meq} / 100 \mathrm{~g}$ de solo; $\mathrm{P}, 20,83$ ppm; e matéria orgânica, $1,20 \%$.

Foram comparados sete cultivares de capimelefante e sete híbridos de capim-elefante com milheto, totalizando 14 tratamentos. O delineamento experimental foi o de blocos ao acaso com três repetições.
As análises estatísticas foram realizadas por intermédio do agrupamento dos dois grupos (cultivares e híbridos), verificando-se as possíveis diferenças entre os mesmos, bem como as diferenças dentro de cada grupo isoladamente. Os dados de número de perfilhos foram transformados em $\sqrt{ } \mathrm{x}$, enquanto os da relação folha/colmo foram transformados em $\log x$ (FERREIRA, 1991). As cultivares selecionadas foram originadas de competição prévia de 73 cultivares de capim-elefante e tinham as seguintes denominações: Mole de Volta Grande, Australiano, Cameroon - IRI, Gramafante, Venezuela, Elefante Roxo e Elefante B. Os sete híbridos foram originados do programa de geração de híbridos do IPA, que consistiu da hibridação entre o elefante-B e duas linhas macho estéreis de milheto: 23A e 5054-A. Neste programa, foram gerados 500 materiais, que foram submetidos a um ensaio preliminar. Os híbridos selecionados deste ensaio para a competição sob pastejo tinham a seguinte denominação: HV-204 (5054A x Elef. B), HV-241 (23A x Elef. B), HV-268 (23A x Elef. B), HV-281 (23A x Elef. B), HV-290 (23A x Elef. B), HV-400 (23A x Elef. B) e HV-296 (23A x Elef. B). A sigla HV significa híbrido proveniente de Vitória de Santo Antão, local onde foi realizado o programa de melhoramento.

O experimento foi implantado em 1995, tendo sido realizados cortes rente ao solo, sem a interferência do animal, até 16 de abril de 1996. Em 23/08/96, foi realizado um pastejo de uniformização, tendo as plantas sido rebaixadas à altura de $40 \mathrm{~cm}$ e adubadas com o equivalente a $300 \mathrm{~kg} / \mathrm{ha}$ da mistura NPK (20-10-20). As parcelas tinham $25 \mathrm{~m}^{2}$ de área e continham cinco filas de $5 \mathrm{~m}$ de comprimento e $1 \mathrm{~m}$ de espaçamento entre as mesmas. As observações foram tomadas aleatoriamente por meio do lançamento de um quadrado de ferro, com lado igual a $1 \mathrm{~m}$, na área central de cada parcela.

A metodologia de avaliação adotada foi descrita por GARDNER (1983) e consistiu de pastejos rápidos, comuns a todas as parcelas, intercalados com períodos de descanso. Os pastejos foram realizados com novilhos de idade variável e peso vivo médio de $255 \pm 13 \mathrm{~kg}$, que foram introduzidos na pastagem após cada mensuração, onde permaneceram o tempo necessário para que a forragem fosse consumida até a altura do corte, ou seja, $40 \mathrm{~cm}$. Todas as mensurações, exceto a altura das plantas, foram realizadas no estrato de forragem superior a $40 \mathrm{~cm}$. O intervalo entre pastejos variou com a altura da forragem e a época do ano. O pastejo, nos períodos chuvoso e seco, iniciou-se quando a altura do clone mais alto 
938 Rev. bras. zootec.

atingiu 1,50 e 1,30 $\mathrm{m}$ de altura, respectivamente, segundo metodologia semelhante à descrita por BOTREL et al. (1994).

As mensurações relativas à forragem foram realizadas antes da entrada dos animais na área. Foram realizadas três mensurações $(14 / 10 / 96,08 / 04 / 97$ e 10/12/97) do número de perfilhos basais e axilares, contando-se todos os perfilhos que se encontravam na área de $1 \mathrm{~m}^{2}$ a ser colhida. Com relação ao diâmetro do colmo, também procederam-se a três mensurações (14/10/96, 19/12/96 e 10/12/97), tomando-se seis medidas de perfilhos basais com o auxílio de um paquímetro à altura de $80 \mathrm{~cm}$.

Foram realizadas cinco avaliações (14/10/96, 19/12/96, 08/04/97, 11/06/97 e 10/12/97) da biomassa superior a $40 \mathrm{~cm}$ e da altura das plantas. A produção de colmos e lâmina foliar foi feita por meio de corte, separação manual e secagem a $65^{\circ} \mathrm{C}$, até peso cons- tante. As bainhas das folhas foram consideradas como componentes do colmo, enquanto as brotações axilares tenras foram consideradas como lâmina foliar. Foi avaliada a média das cinco avaliações da relação lâmina foliar/colmo. A altura da planta foi determinada com o auxílio de uma régua de madeira, tendo sido medida a altura até o ápice, tomando-se seis plantas ao acaso em cada parcela.

\section{Resultados e Discussão}

Os dados de altura das plantas são mostrados na Tabela 1. As cultivares de capim-elefante apresentaram sempre maior altura que os híbridos, que dentro destas não diferiram entre si. O híbrido HV-281 apresentou, em média, altura superior à do HV-204, HV-241, HV-268 e HV-400. HANNA (1994) cita como desejável a altura das plantas entre 1 e $2 \mathrm{~m}$, visto

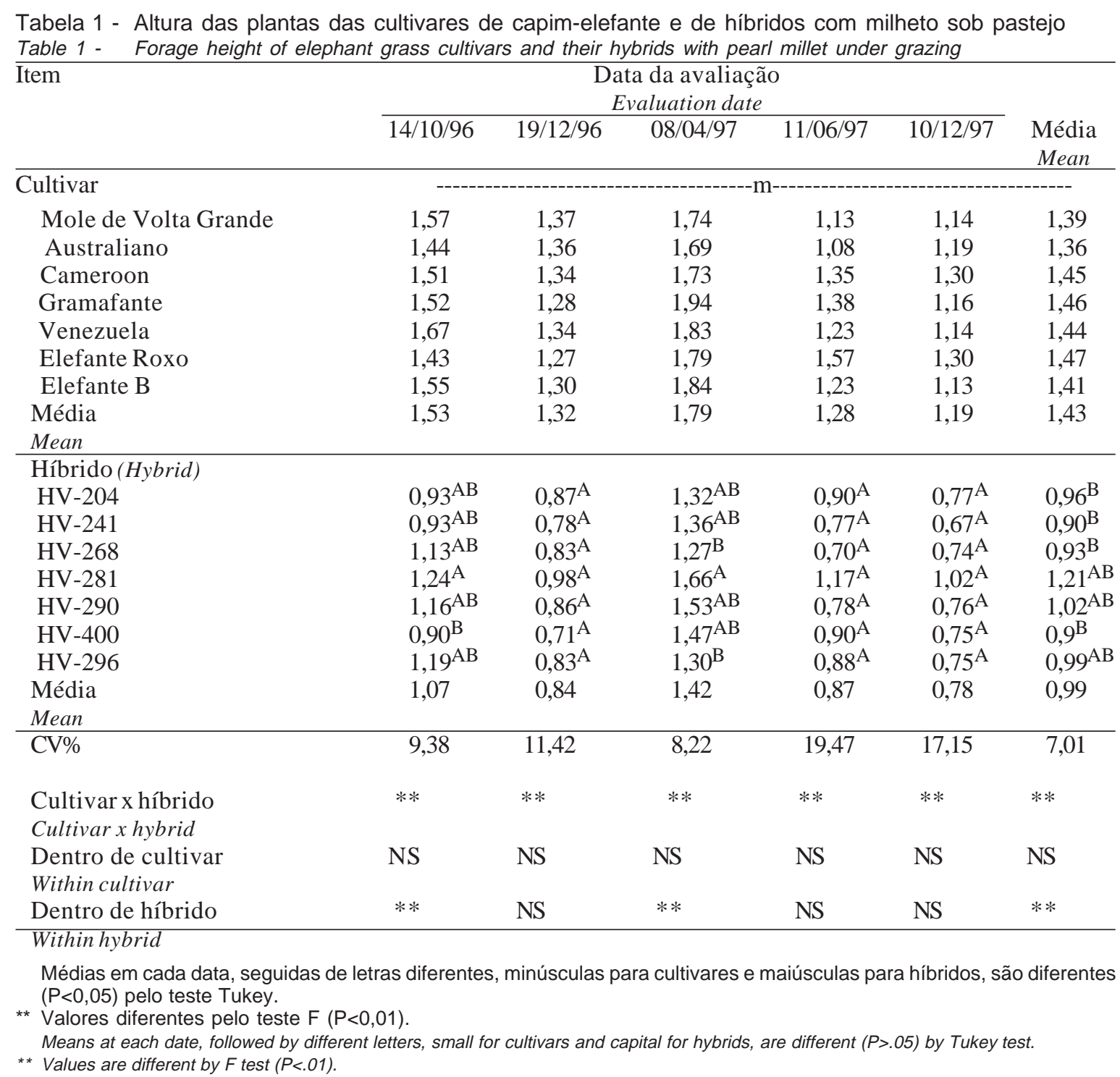


que os genótipos desta altura são mais produtivos que os de menos de $1 \mathrm{~m} \mathrm{e}$, ao mesmo tempo, têm melhor qualidade de forragem. Todos os sete clones de capimelefante apresentaram-se em todas as avaliações dentro deste intervalo de altura da planta. Dos híbridos, por outro lado, só o HV-281 apresentou-se em todos os cortes dentro desta amplitude.

O número de perfilhos basais e axilares em 14/10/96, 08/04/97 e 10/12/97 foi contado, tendo sido constatado, conforme Tabelas 2 e 3, que o número dos dois tipos de perfilhos foi sempre superior, em média, no grupo híbridos de milheto com capim-elefante. Isto, provavelmente, ocorreu em virtude da maior precocidade dos híbridos, florescendo rapidamente, quebrando assim a dominância do meristema apical e estimulando o perfilhamento. Dos híbridos, o HV-204 destacou-se com média de 118 e 165 perfilhos basais e axilares por $\mathrm{m}^{2}$, respectivamente. O Elefante B foi a cultivar de maior número, com 33 e 69 perfilhos basais e axilares por $\mathrm{m}^{2}$, respectivamente. Por outro lado, conforme pode ser visto na Tabela 4, o número de perfilhos axilares por perfilho basilar, em média, não apresentou diferença significativa. O capimelefante B, um dos mais antigos sob cultivo no Brasil, apresentou maior número de perfilhos axilares que as cultivares Cameroon, Gramafante, Venezuela e Elefante Roxo, indicando ser um dos mais recomendáveis para pastejo, pois, de acordo com CORSI (1993), o consumo de forragem é elevado quando há predominância deste tipo de perfilho. Os resultados também indicam que o grupo dos híbridos é bem adaptado ao pastejo. O número de perfilhos basais do grupo cultiva-

Tabela 2 - Número de perfilhos basilares em cultivares de capim-elefante e híbridos com milheto sob pastejo Table 2 - Number of basal tillers of elephant grass cultivars and their hybrids with pearl millet under grazing

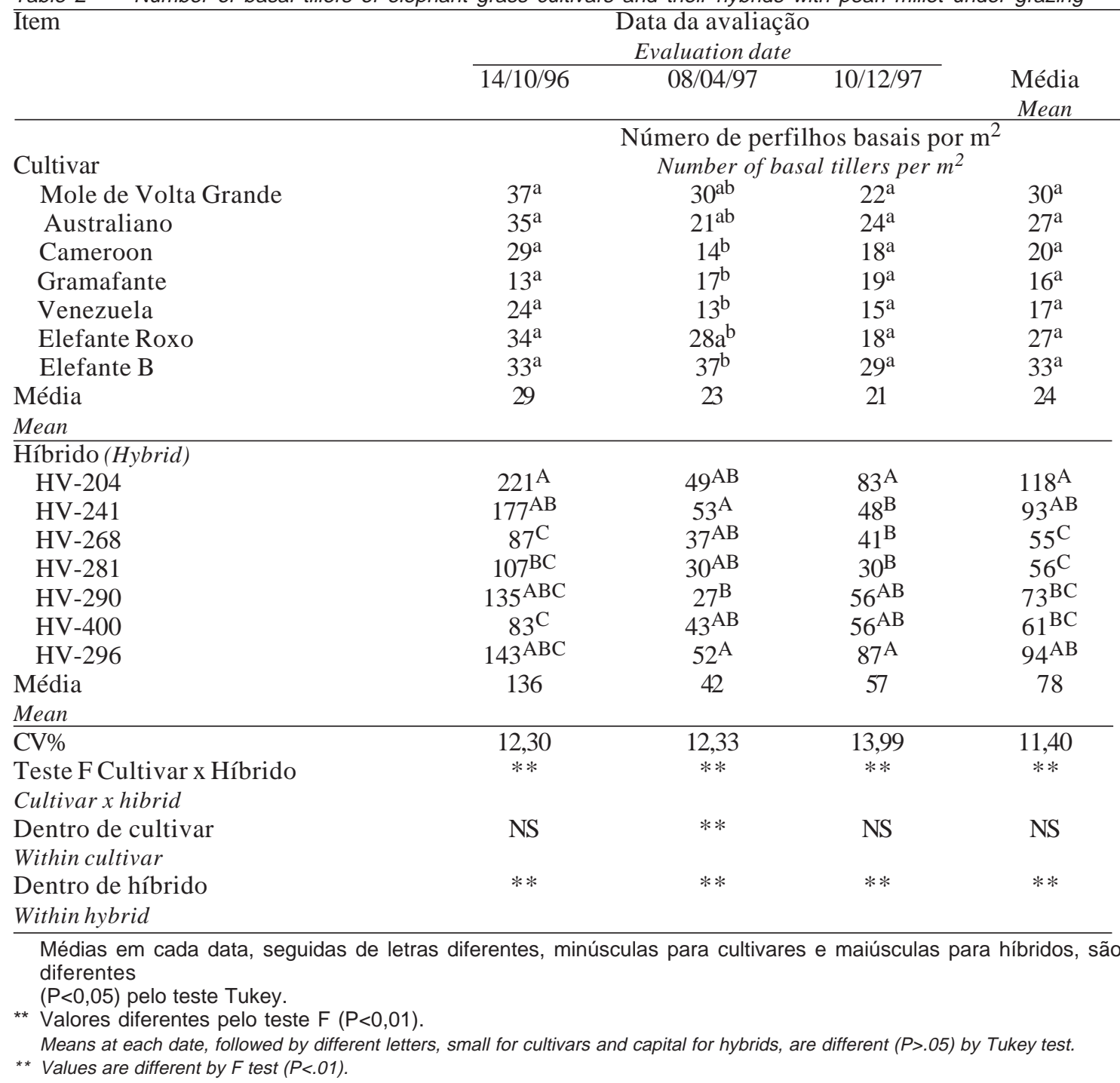


940 Rev. bras. zootec.

Tabela 3 - Número de perfilhos axilares em cultivares de capim-elefante e híbridos com milheto sob pastejo

Table 3 - Number of lateral tillers of elephant grass cultivars, and their hybrids with pearl millet under grazing Item Data da avaliação

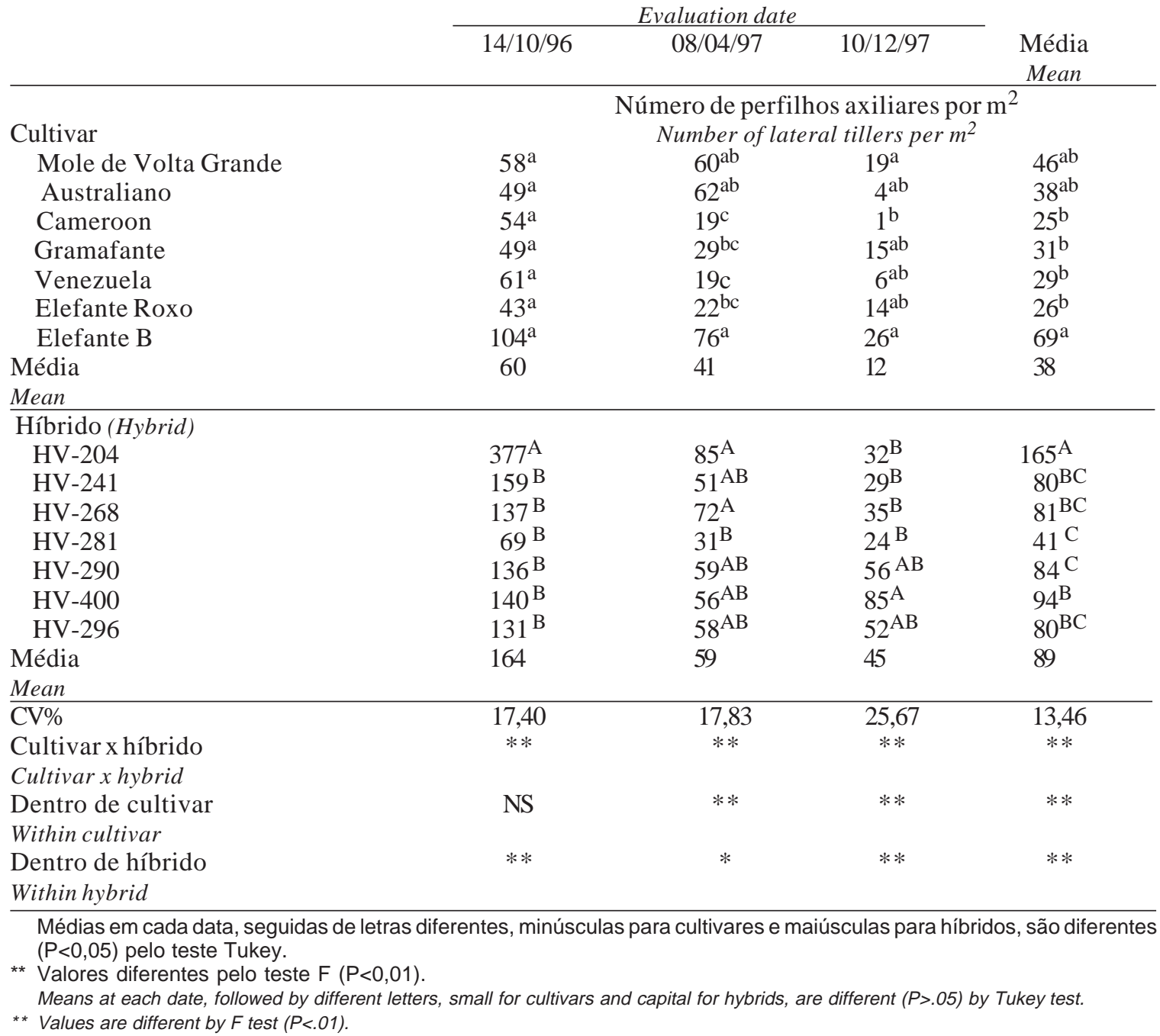

res $\left(24\right.$ por $\left.\mathrm{m}^{2}\right)$ foi semelhante ao detectado por BOTREL et al. (1994), mas o número de perfilhos axilares foi inferior ao observado no trabalho acima citado. Possivelmente, o menor número de perfilhos axilares por perfilho basilar deste trabalho, seja conseqüência de menor potencial de crescimento do capimelefante no experimento da Zona-da-Mata Seca de Pernambuco, quando comparado ao trabalho realizado na Zona-da-Mata mineira. Observou-se, também, no decorrer do trabalho, alta mortalidade dos perfilhos axilares na época seca.

Os dados de diâmetro do colmo são mostrados na Tabela 5. As cultivares tiveram colmo de maior diâmetro em todas as observações, quando comparadas aos híbridos, sendo a diferença altamente significativa $(\mathrm{P}<0,05)$. As cultivares Cameroon, Gramafante, Venezuela e Elefante Roxo destacaram-se com diâ- metro médio superior a $10 \mathrm{~mm}$, enquanto as outras três tiveram diâmetro do colmo entre 7 e $9 \mathrm{~mm}$. Os híbridos, como grupo, apresentaram média de $4,72 \mathrm{~mm}$, sendo o HV-241, com 5,74 mm, o de maior diâmetro e o HV-400, com 4,02 mm, o de menor diâmetro. Os híbridos de milheto tiveram como progenitores linhas macho estéreis 5054A e 23A, que têm colmos finos, e o Elefante B, que foi a variedade de colmo mais fino dentre os capins-elefante estudados, o que pode explicar o menor diâmetro do colmo dos híbridos.

A produção total de matéria seca das cultivares de capim-elefante foi de 6,95 t/ha•ano e a dos híbridos, 3,80 t/ha/ano, sendo esta diferença significativa $(\mathrm{P}<0,05)$, conforme pode ser visto na Tabela 6 . Por outro lado, não ocorreram diferenças significativas quando as cultivares de capim-elefante e os híbridos foram comparados dentro de cada grupo. 
LIRA et al.

Tabela 4 - Número de perfilhos axilares por perfilho basilar em cultivares de capim-elefante e híbridos com milheto sob pastejo

Table 4 - Number of lateral tillers/basal tiller in elephant grass cultivars and their hibrids with pearl millet under grazing

\begin{tabular}{|c|c|c|c|c|}
\hline \multirow[t]{2}{*}{ Item } & \multicolumn{3}{|c|}{$\begin{array}{l}\text { Data da avaliação } \\
\text { Evaluation dates }\end{array}$} & \multirow[b]{2}{*}{$\begin{array}{l}\text { Média } \\
\text { Mean }\end{array}$} \\
\hline & $14 / 10 / 96$ & 08/04/97 & $10 / 12 / 97$ & \\
\hline Cultivar & \multicolumn{4}{|c|}{$\begin{array}{l}\text { Número de perfilhos axiliar/perfilho basilar } \\
\text { Number of lateral tillers/basal tiller }\end{array}$} \\
\hline Mole de Volta Grande & $1,61^{\mathrm{b}}$ & $2,09^{\mathrm{a}}$ & $0,90^{\mathrm{a}}$ & $1,53^{\mathrm{a}}$ \\
\hline Australiano & $1,43^{b}$ & $3,37^{\mathrm{a}}$ & $0,16^{\mathrm{a}}$ & $1,65^{\mathrm{a}}$ \\
\hline Cameroon & $1,82^{\mathrm{ab}}$ & $1,95^{\mathrm{a}}$ & $0,06^{\mathrm{a}}$ & $1,27^{\mathrm{a}}$ \\
\hline Gramafante & $3,81 \mathrm{a}$ & $1,83^{\mathrm{a}}$ & $0,83^{\mathrm{a}}$ & $2,16^{\mathrm{a}}$ \\
\hline Venezuela & $2,90^{\mathrm{ab}}$ & $1,52^{\mathrm{a}}$ & $0,43^{\mathrm{a}}$ & $1,62^{\mathrm{a}}$ \\
\hline Elefante Roxo & $1,50^{\mathrm{b}}$ & $0,81^{\mathrm{a}}$ & $0,88^{\mathrm{a}}$ & $1,06^{\mathrm{a}}$ \\
\hline Elefante B & $3,20^{\mathrm{ab}}$ & $2,14^{\mathrm{a}}$ & $0,94^{\mathrm{a}}$ & $2,09^{\mathrm{a}}$ \\
\hline Média & 2,32 & 1,96 & 0,60 & 1,63 \\
\hline \multicolumn{5}{|l|}{ Mean } \\
\hline \multicolumn{5}{|l|}{ Híbrido (Hybrid) } \\
\hline HV-204 & 1,81 & 1,87 & 0,43 & 1,37 \\
\hline HV-241 & 0,90 & 0,92 & 0,61 & 0,81 \\
\hline HV-268 & 1,71 & 2,11 & 0,92 & 1,58 \\
\hline HV-281 & 0,65 & 0,98 & 0,82 & 0,82 \\
\hline HV-290 & 1,11 & 2,34 & 1,00 & 1,48 \\
\hline HV-400 & 1,84 & 1,33 & 2,24 & 1,80 \\
\hline HV-296 & 0,88 & 1,12 & 0,63 & 0,88 \\
\hline Média & 1,27 & 1,52 & 0,95 & 1,25 \\
\hline \multicolumn{5}{|l|}{ Mean } \\
\hline CV\% & 19,65 & 24,96 & 39,44 & 17,01 \\
\hline Cultivar x híbrido & ** & NS & * & NS \\
\hline Cultivar $x$ hybrid & & NS & & \\
\hline Dentro de cultivar & ** & & $*$ & NS \\
\hline \multicolumn{5}{|l|}{ Within cultivar } \\
\hline Dentro de híbrido & NS & NS & NS & NS \\
\hline Within hybrid & & & & \\
\hline
\end{tabular}

Médias em cada data, seguidas de letras diferentes, minúsculas para cultivares e maiúsculas para híbridos, são diferentes

$(P<0,05)$ pelo teste Tukey.

** Valores diferentes pelo teste $\mathrm{F}(\mathrm{P}<0,01)$.

Means at each date, followed by different letters, small for cultivars and capital for hybrids, are different $(P>.05)$ by Tukey test.

** Values are different by $F$ test $(P<.01)$.

Como citado anteriormente, este experimento, por estar sendo submetido, desde 1995, a um regime de cortes, apresentou dados que representam o que acontece quando uma capineira é transformada em área para pastejo. Possivelmente, o manejo anterior pode explicar, em parte, as baixas produções observadas, quando os dados são comparados aos da literatura (BOTREL et al., 1994). Por outro lado, PORTELA et al. (1995) determinaram, em pleno período de crescimento, que a disponibilidade do capim-elefante passou de 0,48 para 1,23 t de MS/ha em 31 dias, o que representa crescimento diário de 24 $\mathrm{kg}$ de MS/ha/dia, semelhante aos $23 \mathrm{~kg}$ de MS/ha•dia detectados para a cv. Venezuela neste trabalho. A superioridade das cultivares de capim-elefante está em acordo com as observações sob corte de GOMIDE et al. (1976). Por outro lado, o germoplasma testado não representa amostra aleatória e não permite obter conclusões generalizadas dos híbridos versus as cultivares. Todas as cultivares de milheto, independente de serem tardias ou precoces em outras latitudes, florescem aos 49-52 dias em Pernambuco. Os híbridos testados foram obtidos pelo cruzamento do capim-elefante $B$, que também floresce precocemente com linhagens de milheto que florescem aos 49 dias. Todos os híbridos obtidos também florescem em curto período, o que contribui para sua menor produtividade, desde que o ciclo esteja associado à altura da planta, e esta à produtividade.

Neste trabalho, a variação em altura da planta 
942 Rev. bras. zootec.

Tabela 5 - Diâmetro do colmo das plantas de cultivares de capim-elefante e híbridos com milheto sob pastejo

Table 5 - Stem diameter of elephant grass cultivars plants and their hibrids with pearl milet under grazing

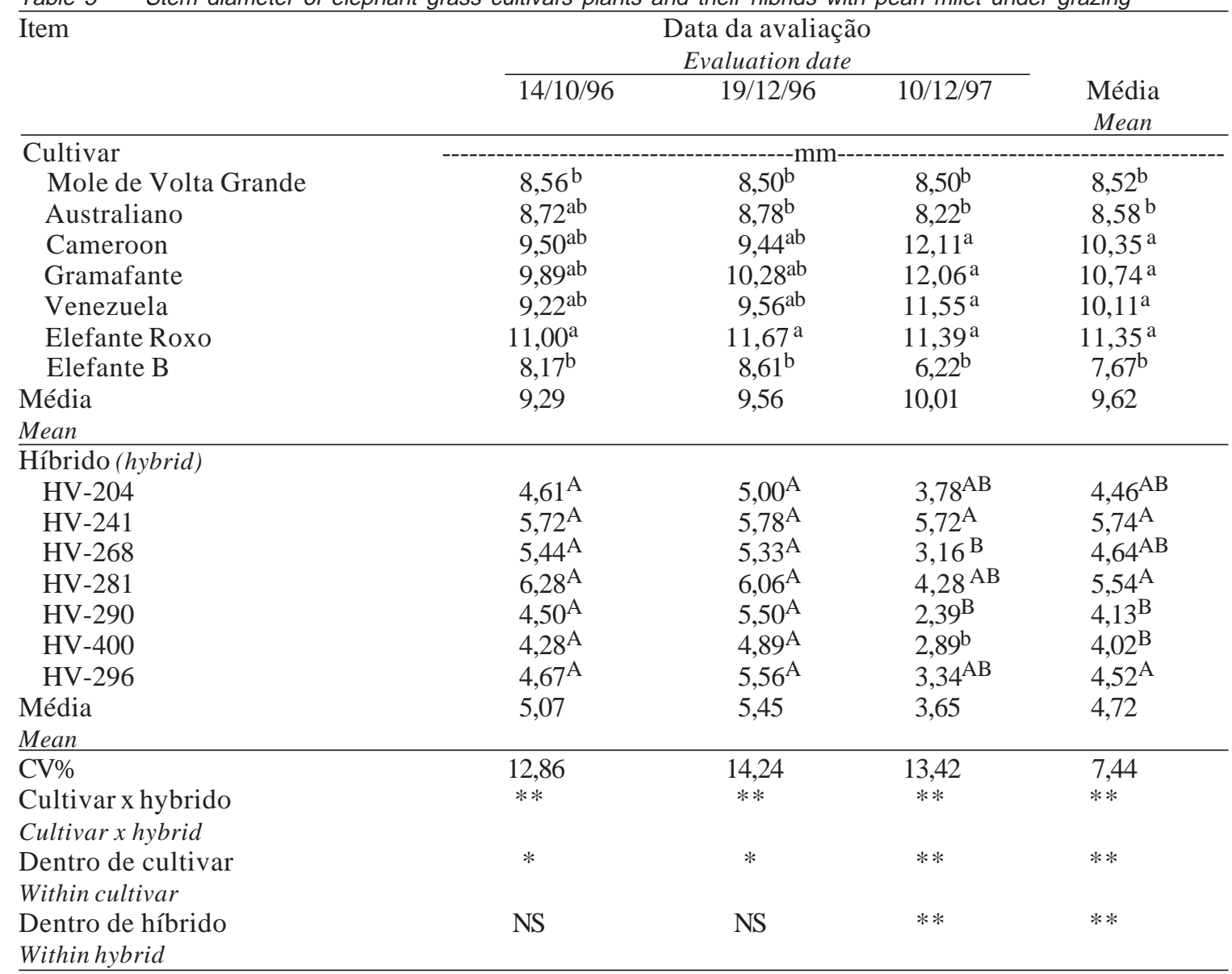

Médias em cada data, seguidas de letras diferentes, minúsculas para cultivares e maiúsculas para híbridos, são diferentes $(\mathrm{P}<0,05)$ pelo teste Tukey.

** Valores diferentes pelo teste $F(P<0,01)$.

Means at each date, followed by different letters, small for cultivars and capital for hybrids, are different (P>.05) by Tukey test.

** Values are different by $F$ test $(P<.01)$.

pode explicar a maior parte da variação de produção entre cortes, tendo o $\mathrm{r}^{2}$ entre estes dois caracteres atingido 0,94 para as cultivares e 0,64 para os híbridos. Outro ponto que merece ser ressaltado é o coeficiente angular da regressão linear da produtividade de matéria seca em relação à altura, a qual, por ser o caráter independente, atingiu 3,71 para cultivares e 1,67 para os híbridos. A diferença indica que as cultivares aumentaram mais em produtividade, com incremento em altura, que os híbridos.

A comparação dos dados de produção de matéria seca com a fase anterior, em que os capins foram submetidos a corte, apresentou coeficiente de correlação de 0,78 . Isto indica que na fase inicial do programa de melhoramento é possível separar os clones promissores por cortes rentes ao solo.

Os dados de produção de lâmina foliar (LF), conforme apresentado na Tabela 7 , evidenciaram a superioridade $(\mathrm{P}<0,05)$ das cultivares, quando comparadas aos híbridos. A variedade de menor potencial, Gramafante, produziu 10,27 kg de MS LF/ha dia e a Venezuela, 19,68 kg, sendo esta diferença altamente significativa $(\mathrm{P}<0,05)$. BOTREL et al. (1994) citam para a variedade Cameroon produção de matéria seca de $34.470 \mathrm{~kg} / \mathrm{ha} \bullet$ ano com 0,61 de relação colmo/folha, ou seja, 56,17 kg de MS folha/ha.dia. A variedade Cameroon produziu neste teste $13,96 \mathrm{~kg}$ MS LF/ha.dia, ou seja, quatro vezes menos que o 
LIRA et al.

Tabela 6 - Produção de Matéria seca das cultivares de capim-elefante e de híbridos com milheto sob pastejo Table 6 - Dry matter yield of elephant grass cultivars and their hibrids with pearl millet under grazing

\begin{tabular}{|c|c|c|c|c|c|c|}
\hline \multirow[t]{2}{*}{ Item } & \multicolumn{5}{|c|}{$\begin{array}{c}\text { Data da avaliação } \\
\text { Evaluation dates }\end{array}$} & \multirow[b]{2}{*}{ Total } \\
\hline & $14 / 10 / 96$ & $19 / 12 / 96$ & $08 / 04 / 97$ & $11 / 06 / 97$ & $10 / 12 / 97$ & \\
\hline Cultivar & \multicolumn{6}{|c|}{$\begin{array}{c}\mathrm{t} \text { de } \mathrm{MS} / \mathrm{ha} \\
\text { t of } D M / h a\end{array}$} \\
\hline Mole de Volta Grande & $2,34^{\mathrm{a}}$ & $1,42^{\mathrm{a}}$ & $3,21^{\mathrm{a}}$ & $1,34^{\mathrm{a}}$ & $1,24^{\mathrm{a}}$ & $9,55^{\mathrm{a}}$ \\
\hline Australiano & $2,42^{\mathrm{a}}$ & $1,33^{\mathrm{a}}$ & $2,99^{\mathrm{a}}$ & $0,88^{\mathrm{a}}$ & $1,01^{\mathrm{a}}$ & $8,63^{\mathrm{a}}$ \\
\hline Cameroon & $2,44^{\mathrm{a}}$ & $1,48^{\mathrm{a}}$ & $2,39^{\mathrm{a}}$ & $0,95^{\mathrm{a}}$ & $1,27^{\mathrm{a}}$ & $8,53^{\mathrm{a}}$ \\
\hline Gramafante & $2,25^{\mathrm{a}}$ & $0,54^{\mathrm{a}}$ & $1,62^{\mathrm{a}}$ & $0,89^{\mathrm{a}}$ & $0,78^{\mathrm{a}}$ & $6,08^{a}$ \\
\hline Venezuela & $3,22^{\mathrm{a}}$ & $1,72^{\mathrm{a}}$ & $4,14^{\mathrm{a}}$ & $0,83^{\mathrm{a}}$ & $1,10^{\mathrm{a}}$ & $11,01^{\mathrm{a}}$ \\
\hline Elefante Roxo & $2,48^{\mathrm{a}}$ & $1,22^{\mathrm{a}}$ & $3,55^{\mathrm{a}}$ & $1,63^{\mathrm{a}}$ & $1,56^{\mathrm{a}}$ & $10,44^{\mathrm{a}}$ \\
\hline Elefante B & $2,16^{\mathrm{a}}$ & $0,93^{\mathrm{a}}$ & $3,74^{\mathrm{a}}$ & $0,82^{\mathrm{a}}$ & $1,21^{\mathrm{a}}$ & $8,86^{\mathrm{a}}$ \\
\hline Média & 2,47 & 1,23 & 3,09 & 1,05 & 1,17 & 9,01 \\
\hline \multicolumn{7}{|l|}{ Mean } \\
\hline \multicolumn{7}{|l|}{ Híbrido (hybrid) } \\
\hline HV-204 & 2,38 & 0,93 & 1,58 & 1,16 & 0,58 & 6,63 \\
\hline HV-241 & 1,75 & 0,35 & 1,46 & 0,63 & 0,31 & 4,50 \\
\hline HV-268 & 1,32 & 0,86 & 1,58 & 0,87 & 0,15 & 4,78 \\
\hline HV-281 & 1,69 & 0,34 & 1,81 & 0,85 & 0,46 & 5,15 \\
\hline HV-290 & 1,50 & 0,79 & 1,07 & 0,74 & 0,38 & 4,48 \\
\hline HV-400 & 1,30 & 0,39 & 1,55 & 0,88 & 0,34 & 4,46 \\
\hline HV-296 & 1,38 & 0,67 & 1,16 & 1,00 & 0,27 & 4,48 \\
\hline Média & 1,62 & 0,62 & 1,46 & 0,87 & 0,36 & 4,93 \\
\hline \multicolumn{7}{|l|}{ Mean } \\
\hline $\mathrm{CV} \%$ & 32,03 & 58,43 & 49,48 & 37,69 & 77,52 & 30,8 \\
\hline Cultivar x híbrido & $* *$ & $* *$ & $* *$ & $\mathrm{NS}$ & $* *$ & $* *$ \\
\hline Cultivar $x$ hybrid & & & & & & \\
\hline $\begin{array}{l}\text { Dentro de cultivar } \\
\text { Within cultivar }\end{array}$ & NS & NS & NS & NS & NS & NS \\
\hline $\begin{array}{l}\text { Dentro de híbrido } \\
\text { Within hybrid }\end{array}$ & NS & NS & NS & NS & NS & NS \\
\hline
\end{tabular}

${ }^{* *}$ Valores diferentes pelo teste $F(P<0,01)$.

** Values are different by $F$ test $(P<.01)$.

relatado por BOTREL et al. (1994). Provavelmente, as razões comentadas para produção de matéria seca também explicam a produção de lâmina foliar.

O germoplasma, para ter elevada produção de lâmina foliar (LF), necessita ter alta produção de biomassa aérea e elevada relação LF/colmo. Sob pastejo, os bovinos têm a possibilidade de selecionar a forragem e, se dada a oportunidade, consomem mais folhas que colmos, o que não acontece se a forragem for fornecida picada no cocho. Assim, a relação LF/ colmo é mais importante para expressar a qualidade da forragem para corte, enquanto a disponibilidade de LF é mais importante para explorações sob pastejo.

A relação LF/colmo apresentou precisão muito baixa e não será relatada para cada corte. O quociente da produção de lâmina foliar pela produção de colmos é apresentado na Tabela 8. As cultivares tinham, em média, maior relação que os híbridos, mas o HV-241 foi o de maior valor. O valor de 4,67 para o elefante roxo foi superior ao observado por DESCHAMPS (1997), que constatou relação de 1,84 para esta variedade aos 28 dias sob regime de corte, no entanto, no presente experimento a relação LF/colmo representou a forragem acima dos $40 \mathrm{~cm}$ de altura. 
944 Rev. bras. zootec.

Tabela 7 - Produção de matéria seca de lâmina foliar em cultivares de capim-elefante e de híbridos com milheto sob pastejo

Table 7 - Leaves blade dry matter yield of elephant grass cultivars and their hibrids with pearl millet under grazing

\begin{tabular}{|c|c|c|c|c|c|c|}
\hline \multirow[t]{2}{*}{ Item } & \multicolumn{5}{|c|}{$\begin{array}{c}\text { Data da avaliação } \\
\text { Evaluation dates }\end{array}$} & \multirow[b]{2}{*}{ Total } \\
\hline & $14 / 10 / 96$ & $19 / 12 / 96$ & $08 / 04 / 97$ & $11 / 06 / 97$ & $10 / 12 / 97$ & \\
\hline Cultivar & \multicolumn{6}{|c|}{ t de MS/ha } \\
\hline Mole de Volta Grande & $1,41^{\mathrm{c}}$ & $1,17^{\mathrm{a}}$ & $2,54^{\mathrm{a}}$ & $1,05^{a b}$ & $0,72^{\mathrm{a}}$ & $6,89^{a b}$ \\
\hline Australiano & $2,01^{a b}$ & $1,12^{\mathrm{a}}$ & $2,33^{\mathrm{a}}$ & $0,73^{a b}$ & $0,74^{\mathrm{a}}$ & $6,93^{\mathrm{ab}}$ \\
\hline Cameroon & $1,22^{\mathrm{c}}$ & $1,33^{\mathrm{a}}$ & $2,13^{\mathrm{a}}$ & $0,88^{a b}$ & $1,03^{\mathrm{a}}$ & $6,59^{a b}$ \\
\hline Gramafante & $1,51^{\mathrm{b}}$ & $0,44^{\mathrm{a}}$ & $1,35^{a}$ & $0,79^{a b}$ & $0,76^{\mathrm{a}}$ & $4,85^{\mathrm{b}}$ \\
\hline Venezuela & $2,47^{\mathrm{a}}$ & $1,52^{\mathrm{a}}$ & $3,52^{\mathrm{a}}$ & $0,76^{\mathrm{ab}}$ & $1,02^{\mathrm{a}}$ & $9,29 \mathrm{a}$ \\
\hline Elefante Roxo & $1,60^{b c}$ & $1,17^{\mathrm{a}}$ & $3,06^{\mathrm{a}}$ & $1,41 \mathrm{a}$ & $0,93^{\mathrm{a}}$ & $8,17^{\mathrm{ab}}$ \\
\hline Elefante B & $1,22^{\mathrm{c}}$ & $0,76^{\mathrm{a}}$ & $2,53^{\mathrm{a}}$ & $0,65 b$ & $0,77^{\mathrm{a}}$ & $5,93^{\mathrm{ab}}$ \\
\hline Média & 1,63 & 1,07 & 2,49 & 0,90 & 0,85 & 6,95 \\
\hline \multicolumn{7}{|l|}{ Mean } \\
\hline \multicolumn{7}{|l|}{ Híbrido (hybrid) } \\
\hline HV-204 & 0,94 & 0,51 & 1,22 & 0,83 & 0,35 & 3,85 \\
\hline HV-241 & 1,11 & 0,33 & 1,35 & 0,56 & 0,43 & 3,78 \\
\hline HV-268 & 0,75 & 0,58 & 1,21 & 0,74 & 0,11 & 3,39 \\
\hline HV-281 & 1,04 & 0,39 & 1,13 & 0,57 & 0,27 & 3,41 \\
\hline HV-290 & 0,75 & 0,43 & 0,60 & 0,48 & 0,15 & 2,39 \\
\hline HV-400 & 0,72 & 0,28 & 0,78 & 0,68 & 0,23 & 2,70 \\
\hline HV-296 & 0,80 & 0,42 & 0,90 & 0,81 & 0,21 & 3,13 \\
\hline Média & 0,87 & 0,42 & 1,03 & 0,67 & 0,25 & 3,23 \\
\hline \multicolumn{7}{|l|}{ Mean } \\
\hline$\overline{\mathrm{CV} \%}$ & 16,31 & 58,28 & 50,21 & 35,59 & 60,73 & 28,17 \\
\hline Cultivar x híbrido & $* *$ & $* *$ & $* *$ & $* *$ & $* *$ & $* *$ \\
\hline Cultivar x hybrid & & & & & & \\
\hline Dentro de cultivar & $* *$ & NS & NS & * & NS & * \\
\hline $\begin{array}{l}\text { Within cultivar } \\
\text { Dentro de híbrido } \\
\text { Within hybrid }\end{array}$ & NS & NS & NS & NS & NS & NS \\
\hline
\end{tabular}

Médias em cada data, seguidas de letras diferentes, minúsculas para cultivares e maiúsculas para híbridos, são diferentes $(\mathrm{P}<0,05)$ pelo teste Tukey.

** Valores diferentes pelo teste $F(P<0,01)$.

Means at each date, followed by different letters, small for cultivars and capital for hybrids, are different $(P>.05)$ by Tukey test.

** Values are different by $F$ test $(P<.01)$. 
LIRA et al.

Tabela 8 - Relação lâmina foliar/colmo em cultivares de capim-elefante e de híbridos com milheto (H) sob pastejo

Table 8 - $\quad$ Leaf blade/stem ratio of elephant grass cultivars and their hibrids with pearl millet under grazing

\begin{tabular}{|c|c|}
\hline Item & $\begin{array}{c}\text { Relação lâmina foliar/colmo } \\
\text { Leaf blade/stem ratio }\end{array}$ \\
\hline \multicolumn{2}{|l|}{ Cultivar } \\
\hline Mole de Volta Grande & 3,37 \\
\hline Australiano & 5,06 \\
\hline Cameroon & 3,54 \\
\hline Gramafante & 4,89 \\
\hline Venezuela & 5,51 \\
\hline Elefante Roxo & 4,67 \\
\hline Elefante B & 2,16 \\
\hline Média & 4,86 \\
\hline \multicolumn{2}{|l|}{ Mean } \\
\hline \multicolumn{2}{|l|}{ Híbrido (hybrid) } \\
\hline $\mathrm{HV}-204$ & $1,54^{\mathrm{B}}$ \\
\hline HV-241 & $6,80^{\mathrm{A}}$ \\
\hline HV-268 & $2,53^{\mathrm{AB}}$ \\
\hline HV-281 & $2,00^{\mathrm{AB}}$ \\
\hline $\mathrm{HV}-290$ & $1,16^{\mathrm{B}}$ \\
\hline $\mathrm{HV}-400$ & $1,36^{\mathrm{B}}$ \\
\hline HV-296 & $2,96^{\mathrm{AB}}$ \\
\hline Média & 3,06 \\
\hline Mean & 44,2 \\
\hline \multicolumn{2}{|l|}{ CV\%* } \\
\hline \multicolumn{2}{|l|}{ Cultivar x híbrido } \\
\hline Cultivar x hybrid & $* *$ \\
\hline \multicolumn{2}{|l|}{ Dentro de cultivar } \\
\hline Within cultivar & NS \\
\hline \multicolumn{2}{|l|}{ Dentro de híbrido } \\
\hline Within hybrid & $* *$ \\
\hline \multicolumn{2}{|c|}{$\begin{array}{l}\text { Médias em cada data, seguidas de letras diferentes, minúsculas para cultivares e maiúsculas para híbridos, são } \\
\text { diferentes } \\
(P<0,05) \text { pelo teste Tukey. } \\
\text { ** Valores diferentes pelo teste } F(P<0,01) \text {. } \\
\text { Means at each date, followed by different letters, small for cultivars and capital for hybrids, are different }(P>.05) \text { by Tukey test. } \\
\text { ** Values are different by } F \text { test }(P<.01) \text {. }\end{array}$} \\
\hline
\end{tabular}

\section{Conclusões}

Os híbridos de capim-elefante com milheto estudados foram menos produtivos que as cultivares e de menores altura e relação lâmina foliar/colmo, mas apresentaram maior número de perfilhos basais e axilares.

Considerando as características de perfilhamento basal e axilar, os híbridos avaliados são bem adaptados ao pastejo, embora menos produtivos que as cultivares de capim-elefante testadas.

\section{Referências Bibliográficas}

ANDRADE, J.C. A produção de leite na microrregião do Vale do Ipojuca-PE: Aspectos nutricionais e econômicos. Recife: UFRPE, 1993. 198p. Dissertação (Mestrado em Produção Animal) - Universidade Federal Rural de Pernambuco, 1993. BOtrel, M.A., ALVIM, M.J., MARTINS, C.E. 1994. Ava- liação e seleção de cultivares de capim-elefante (Pennisetum purpureum, Schum.) para pastejo. R. Soc. Bras. Zootec., 23(5):754-762.

CORSI, M. Manejo de capim-elefante sob pastejo. In: SIMPÓSIO SOBRE MANEJO DA PASTAGEM, 10, 1993, Piracicaba. Anais... Piracicaba: ESALQ, 1993. p.143-168.

DERESZ, F., MOZZER, O.L., CÓSER, A.C. 1998. Manejo de pastagem do capim-elefante para produção de leite. Inf. Agropec., 19(192):55-61.

DESCHAMPS, F.C. Perfil fisiológico de três ecotipos de capimelefante (Pennisetum purpureum, Schum.). In: REUNIÃO ANUAL DA SOCIEDADE BRASILEIRA DE ZOOTECNIA, 34, 1997, Juiz de Fora. Anais... Juiz de Fora: SBZ, 1997. p.62-64.

EMBRAPA 1979. Manual de métodos de análise de solos, parte 3, análise de fertilidade. EMBRAPA/SNLCS: Rio de Janeiro. 17p.

FERREIRA, P.V. 1991. Estatística experimental aplicada à agricultura. Univ. Fed. de Alagoas, Centro de Ciências Agrárias, Maceió, Alagoas. 44p.

GARDNER, A.L. 1983. Evaluación por corte y por pastoreo en parcelas pequeñas, comparación de resultados. In: PADINES, 
946 Rev. bras. zootec.

O, LASCANO, C. (Eds.). Germoplasma forragero bajo pastoreo en pequeñas parcelas. Metodologias de evaluación. Cali: CIAT. p.107-120

GOMIDE, J.A., CHRISTMAS, E.P., OBEID, J.A. 1976. Competição de quatro variedades de capim-elefante e seus híbridos com Pearl Millet 239 DA-2. R. Soc. Bras. Zootec., 5(2):226-247.

HANNA, W.W. Elephant grass improvement. In: SIMPÓSIO SOBRE CAPIM ELEFANTE, 2., 1994, Juiz de Fora. Anais... Coronel Pacheco, MG:EMBRAPA-CNPGL, 1994. p.72-81.

LIRA, M.A., FARIAS, I., SANTOS, M.V.F. Alimentação de bovinos no Nordeste - Experimentação com forrageiras e pastagens. In: SIMPÓSIO NORDESTINO DE ALIMENTAÇÃO DE RUMINANTES, 1990, João Pessoa. Anais... João Pessoa, s.ed., 1990. p.108-133.

MACIEL, G.A., TABOSA, J.N. 1982. Tecnologia de produção para o milheto. In: Cultura do milheto. Fortaleza: BNB/ETENE (Monografias, 8). p.23-35.

MARTINS, C.E.. FONSECA, D.M. 1998. Manejo e fertilidade do solo em pastagens de capim-elefante. Inf. Agropec., 19(192):44-54.

MONTEIRO, F.A., WERNER, J.C. Reciclagem de nutrientes em pastagens. In: SIMPÓSIO BRASILEIRO DEFORRAGEIRAS EPASTAGENS, 1994, Campinas. Anais... Campinas: Colégio Brasileiro de Nutrição Animal, 1994. p.41-65.
PORTELA, J.N., OLIVO, C.J., MICHELLON, T. et al. Desempenho de novilhas e vacas em lactação submetidas ao pastejo em cultivares de capim-elefante. In: REUNIÃO ANUAL DA SOCIEDADE BRASILEIRA DE ZOOTECNIA, 34, 1995, Brasília. Anais... Viçosa: SBZ, 1997, p.127-129.

VALLE, C.B., SOUZA, F.H.D. Construindo novos cultivares de gramíneas forrageiras para os cerrados brasileiros. In: REUNIÃO ANUAL DA SOCIEDADE BRASILEIRA DE ZOOTECNIA, 32, Brasília. Anais...Viçosa: SBZ, 1995. p.3-7.

Recebido em: 21/08/98

Aceito em: 04/02/99 